\title{
Development of a Novel Hybrid Aluminum-Based Sol-Gel Materials: Application to the Protection of AA2024-T3 Alloys in Alkaline Environment
}

\author{
Mohamed Oubaha1, Padinchare Covilakath Rajath Varma ${ }^{1}$, Brendan Duffy ${ }^{1}$, \\ Zuhair Mattoug Gasem², Steven J. Hinder ${ }^{3}$ \\ ${ }^{1}$ Centre for Research in Engineering Surface Technology (CREST), FOCAS Institute, Dublin Institute of \\ Technology, Dublin, Ireland \\ ${ }^{2}$ Centre for Research Excellence in Corrosion, King Fahd University of Petroleum and Minerals, \\ Dhahran, KSA \\ ${ }^{3}$ The Surface Analysis Laboratory, Faculty of Engineering and Physical Sciences, University of Surrey, \\ Guildford, UK \\ Email: 452818@dit.ie
}

Received 26 March 2014; revised 29 April 2014; accepted 7 May 2014

Copyright (C) 2014 by authors and Scientific Research Publishing Inc.

This work is licensed under the Creative Commons Attribution International License (CC BY).

http://creativecommons.org/licenses/by/4.0/

(c) (i) Open Access

\section{Abstract}

Extensive research on environmentally complaint sol-gel coatings is currently underway for a wide range of applications. Sol-gel technology combines the synergistic properties of inorganic and organic components to design nanostructured coating materials with advanced physical properties. Through a judicious choice of precursors and additives improved performances, such as chemical resistance or $\mathrm{pH}$ stability, it can be achieved. This is of particular interest for copper rich AA 2024-T3 aluminium alloys used on aircraft, where increase in local $\mathrm{pH}$ occurs at corrosion sites. This work focuses on improving the alkaline stability and anticorrosion properties of such a sol-gel coatings on AA2024-T3 by incorporating aluminium functionality into hybrid materials prepared from hydrolysis and condensation of 3-methacryloxypropyltrimethoxysilane, zirconium n-propoxide and zirconium/alkoxide precursors. Dynamic light scattering technique was used to study the particle size nature of the sol-gel materials in colloidal form. X-ray photoelectron spectroscopy was used to study the oxidation state of the aluminium and zirconium at the sol-gel coating surface. Field emission scanning electrochemical microscopy coupled with energy dispersive spectroscopy was used to assess the microstructural features. Electrochemical characterisations employing potentiodynamic scanning and electrochemical impedance spectroscopy were performed to investigate the anticorrosion performance of the hybrid sol-gel coatings. The best anticorrosive protection of AA2024-T3 in an alkaline saline solution $(\mathrm{pH}=10)$ was achieved with ma- 
terials containing $10 \mathrm{~mol} \%$ and $15 \mathrm{~mol} \%$ aluminium doped sol-gel coatings. This study shows that presence of aluminium has a positive effect on alkaline stability of the coatings and is a potential green candidate for the protective coatings on aerospace alloys.

\section{Keywords}

\section{Sol-Gel, Aluminium, Zirconium, Corrosion, Coatings, Hybrid: Organo-Silane}

\section{Introduction}

Commercial aircraft fuselage skins are conventionally manufactured using the AA2024-T3 grade aerospace alloy which contains high levels of copper rich secondary phase particles. The copper intermetallics enhance the mechanical strength of AA2024-T3 but increase its corrosion susceptibility. The most effective state of the art technology for protecting such alloys involves the use of hexavalent chromium (Cr(VI)) [1]. However, in the interest of human health and environmental concerns, alternative solutions are being pursued [2] [3]. For engineering applications organic polymers (polyesters, polyamides, alkyds, polyurethane) [4], conductive polymers (polyaniline and polypyrrole) [4] [5] and silane-based sol-gel materials have emerged as promising Cr(VI) alternatives [6]-[8].

The sol-gel process can be used to form nanostructured inorganic coatings (typically $200 \mathrm{~nm}$ to $10 \mu \mathrm{m}$ in overall thickness) that are more resistant than metals to oxidation, corrosion, erosion and wear while also possessing good thermal and electrical properties [7]. The most commonly used hybrid sol-gel materials as coatings are those based on organically modified silicates (Ormosils), which are formed through hydrolysis and condensation reactions of organically functionalized alkoxysilane precursors [9] [10]. Such coatings when cured are chemically inert, but silane bonds are susceptible to degradation at high $\mathrm{pH}$, as hydroxyl groups present react with hydrogens from unreacted silanol groups within the structure. These silanols then become ionized and form a viscous gel that destabilise the coating surface. Consequently, the use of precursors with higher reactivities such as those based on zirconium and titanium chemistries have been exploited [11] [12]. These precursors reduce the number of available silanol groups through hydroxyl scavenging, delivering a coating with improved performance.

The synergistic combination of ormosils and zirconium chemistries improves the alkaline resistance of sol-gel coatings [13]-[15]. The alkaline resistance and self healing barrier properties of the zirconium rich silane coatings have been proven to result from the continuous repetitive process of cleavage and formation of oxane bonds, in the event of alkaline penetration into the sol-gel [16]. This process is important due to local $\mathrm{pH}$ increase in the event of cathodic corrosion and consequent oxygen reduction reaction (ORR) on copper rich aluminium alloys [17]. The use of conventional corrosion inhibitors within such sol-gel coatings has been actively investigated. Multivalent metals such as manganese [18], vanadium [19], cerium [20] [21] and molybdenum [22] have been heavily researched in both the US and Europe. Pore blocking chemistries, using magnesium [23] and zinc [24], were also investigated and found that the formation of insoluble hydroxides prevented corrosive ion ingress through silane based sol-gel coatings. To date little research has been conducted using aluminium additives in silane coatings. One study found the addition of aluminium pigments into silane matrix improved the silane coating stability in alkaline medium [25]. It is demonstrated that the pigments reduced the hydrogen evolution of the sol-gel coatings when exposed to $\mathrm{pH} 11$ conditions.

The aim of this study is to investigate the effect of the inclusion of aluminium nanoparticles within a hybrid organosilane-zirconium sol-gel material on the anticorrosion activity of coatings deposited on AA 2024-T3 panels. These materials were developed employing three reactive sol-gel precursors, namely, methacryloxypropyltrimethoxysilane (MAPTMS), zirconium propoxide (TZPO) and aluminium-zirconium propoxide (AZPO). By maintaining a constant level of metal precursors at $20 \mathrm{~mol} \%$ against the organosilane, the concentration of aluminium was altered and its effect on the coating performance studied. The particle size of the colloidal sol-gel solution was measured using dynamic light scattering technique (DLS). The chemical composition of the coated surface at the air/sol-gel coating interface was assessed using X-ray photoelectron spectroscopy (XPS). The micro-structural characteristics were investigated using field-emission scanning electrochemical microscopy (FE- 
SEM) and elemental analysis was performed energy dispersive spectroscopy (EDS). Visual images and potentiodynamic scanning were used to study the alkaline stability and anticorrosion protection behaviour of the developed coatings.

\section{Experimental}

\subsection{Materials Development}

The materials were developed employing three reactive sol-gel precursor: 3-trimethoxysilylpropylmethacrylate

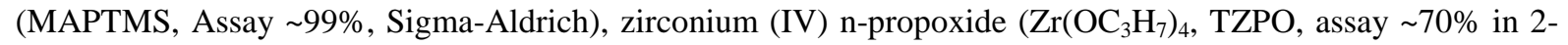
propanol, Sigma-Aldrich), aluminium-zirconium propoxide $\left(\mathrm{Al}_{2} \mathrm{Zr}\left(\mathrm{OC}_{3} \mathrm{H}_{7}\right)_{6}\right.$, AZPO, assay $~ 60 \%$ in 2-propanol, ABCR) and methacrylic acid (MAAH, $\mathrm{C}_{4} \mathrm{H}_{6} \mathrm{O}_{2}$, Assay $>98 \%$, Sigma-Aldrich), utilised as chelating agent. All precursors were used as purchased, without further purification. As these precursors exhibit different reactivities to hydrolysis and condensation, a three-step process was established to avoid formation of any undesired particle that can significantly alter the initial defined molar ratio, as sketched in Figure 1. MAPTMS was firstly pre-hydrolysed using an aqueous solution of $0.01 \mathrm{~N} \mathrm{HNO}_{3}$ for 45 minutes in a reaction vessel A. Both TZPO and AZPO were chelated separately employing MAAH using stoichiometric proportions (1:1 molar ratio) in reaction vessels B and C, respectively for 10 min. Step 3 involved mixing the contents of B and C in the reaction vessel $\mathrm{D}$ for $35 \mathrm{~min}$. The contents of $\mathrm{D}$ and A were then agitated for 45 min followed by a dropwise addition of neutral deionised water (pH 7). In order to complete the hydrolysis and condensation reactions, the resultant sols were left stirring 24 hours before use. The final molar proportions of MAPTMS:MAAH:TZPO/AZPO: $\mathrm{H}_{2} \mathrm{O}$ was 2.5:1:1:5 doped with aluminium (0 mol\%, $5 \mathrm{~mol} \%, 10 \mathrm{~mol} \%, 15 \mathrm{~mol} \%$, and $20 \mathrm{~mol} \%$ ). Shorthand notation for the coatings will rely on the level of aluminium, i.e. $5 \% \mathrm{Al}$ will be used to represent hybrid coating doped with 5 mol\% of aluminium. The molar proportions of the all developed materials are shown in Table 1.

\subsection{Preparation of Sol-Gel Coatings}

AA2024-T3 aluminium panels $(150 \mathrm{~mm} \times 100 \mathrm{~mm})$ were sourced from Amari Irl, Clondalkin. The panels were

Table 1. Chemical composition of the various developed materials.

\begin{tabular}{cccc}
\hline MAPTMS & TZPO & AZPO & Al/Zr (mol. ratio) \\
\hline 80 & 20 & 0 & 0 \\
80 & 15 & 5 & 0.5 \\
80 & 10 & 10 & 1 \\
80 & 5 & 15 & 1.5 \\
80 & 0 & 20 & 2 \\
\hline
\end{tabular}

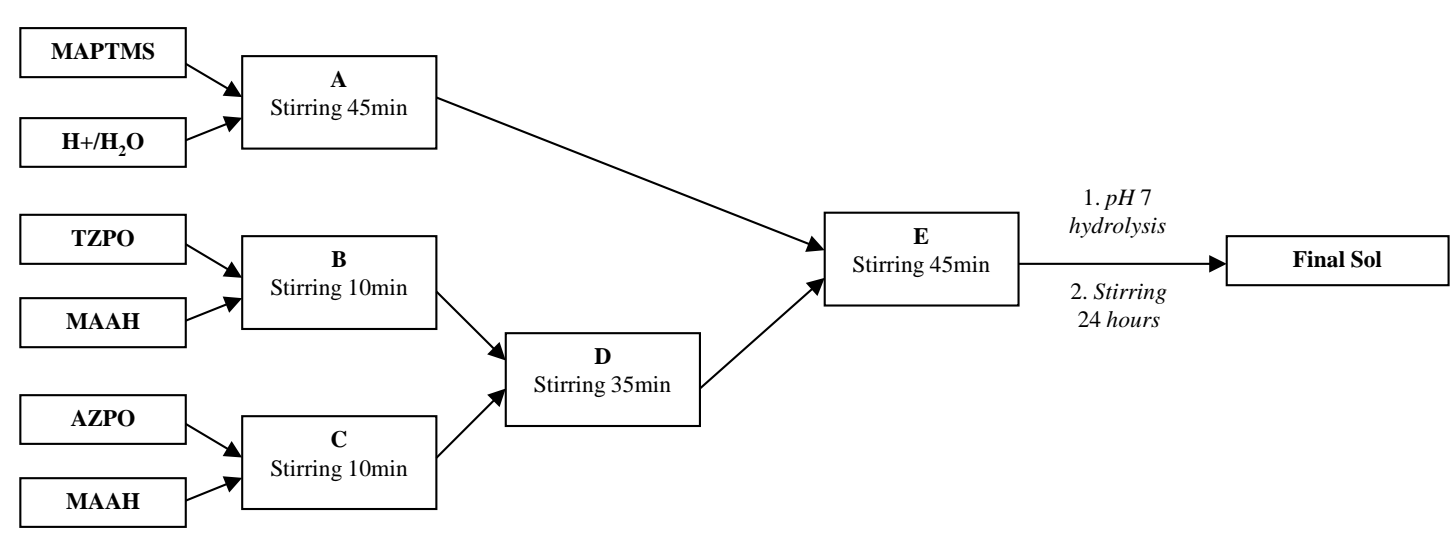

Figure 1. Flow chart for the development of hybrid sol-gel materials. 
degreased with 2-propanol, alkaline cleaned using Oakite $61 \mathrm{~B}^{\circledR}$ (Chemetall, UK) by immersion at $60^{\circ} \mathrm{C}$ for 1 minute and washed in warm deionised water. Any smut was removed by washing in $10 \%$ nitric acid (Sigma, Ireland) followed by rinsing in deionised water. The various sol-gel solutions were filtered using a $0.45 \mu \mathrm{m}$ syringe filter and deposited by spin-coating on AA 2024-T3 alloy at $1000 \mathrm{rpm}$ and thermally stabilised for $12 \mathrm{hr}$ at $100^{\circ} \mathrm{C} \pm 5^{\circ} \mathrm{C}$. The final thickness of all sol-gel coating was $5 \mu \mathrm{m}( \pm 0.5 \mu \mathrm{m})$, as measured using an Elcometer ${ }^{\circledR}$ non destructive coating thickness gauge.

\subsection{Characterisation Techniques}

Colloidal sol-gel particle sizes were determined using a Malvern Nano-ZS instrument, using the dynamic light scattering (DLS) technique. The technique is a well-established optical method used to study dynamic processes of liquids and solids based on Brownian motion. The experiments were conducted at ambient temperature.

XPS analyses were performed using Thermo VG Scientific (East Grinstead, UK) ESCALAB Mk II spectrometer. This instrument was equipped with an XR4 twin anode X-ray source (AlK $\alpha / \mathrm{MgK} \alpha)$ and an Alpha 110 analyser. The twin anodes, $\mathrm{Al} \mathrm{K \alpha} \mathrm{X}$-ray source $(\mathrm{h} v=1486.6 \mathrm{eV})$, were operated at $300 \mathrm{~W}(15 \mathrm{kV} \times 20 \mathrm{~mA})$ for all analyses. For all survey spectra a pass energy of $100 \mathrm{eV}$ was employed. The pass energy was set at $20 \mathrm{eV}$ for the acquisition of all high resolution, core level spectra. Sample mounting for XPS analysis was achieved by fixing a specimen to a VG sample stub using double sided adhesive tape. Quantitative surface chemical analyses were calculated from the spectra following the removal of a non-linear (Shirley) background. All spectra were referenced against the $\mathrm{C} 1 \mathrm{~s}$ peak at $285 \mathrm{eV}$ to correct for charging effects during acquisition.

SEM images were recorded using a Hitachi SU-70 Field Emission Microscope, with electron beam energy of $5 \mathrm{keV}$ and a magnification of up to 11,000×. The FE-SEM was equipped with EDS spectrometer (Oxford instrument INCA $\times 450$ system fitted with silicon drift detector). The cross section of the coated sample was mounted on a carbon stud and coated to gold with a thickness of $\sim 2.2 \mathrm{~nm}$, to ensure the sample was conductive for imaging purposes.

The electrochemical properties of the sol-gel coatings give vital early information on the potential long term performance in aggressive challenging environments. Potentiodynamic scanning (PDS) is a DC technique that gives useful information on a coatings ability to resist corrosion against a voltage gradient. The electrochemical data was obtained using a Solartron SI 1287/1255B system comprising of frequency analyser and potentiostat. PDS was performed using an electrochemical cell (PAR K0235 Flat Cell) with an exposed area of $0.78 \mathrm{~cm}^{2}$ in a continually aerated Harrison's solution (3.5\% $\mathrm{NaCl}$ adjusted to $\mathrm{pH} 10$ with $\mathrm{NaOH}$ solution) where the coated metal acted as a working electrode, a silver/silver chloride ( $\mathrm{Ag} / \mathrm{AgCl})$ electrode was used as a reference electrode and platinum mesh as a counter electrode. All scans were acquired in the region from -0.4 to $+0.5 \mathrm{~V}$ vs. Eoc, with a scan rate $20 \mathrm{mV} / \mathrm{s}$ at room temperatures $\left(20^{\circ} \mathrm{C} \pm 2^{\circ} \mathrm{C}\right)$.

\section{Result and Discussion}

Figure 2 shows the particle size distribution of all developed materials, as characterised employing DLS tech-

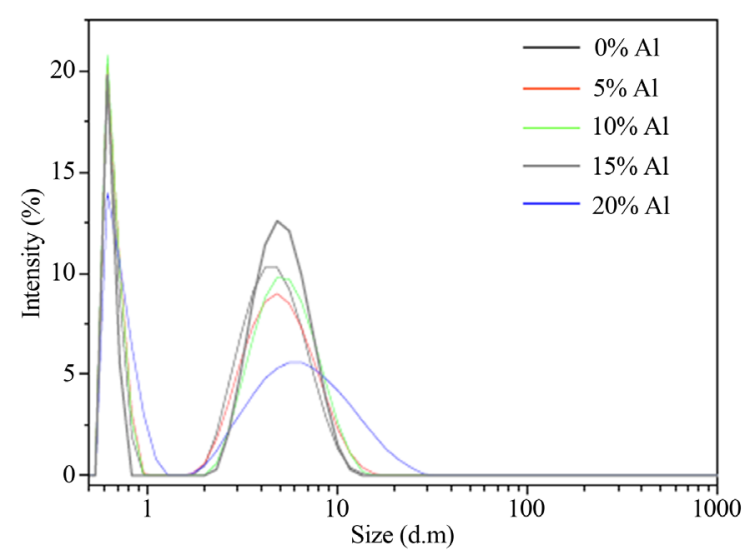

Figure 2. Particle size results of sols doped with various concentrations of aluminium nanoparticles. 
nique. It can be observed the presence of two distinct particle distribution bands located in the ranges $0.6-0.9$ $\mathrm{nm}$ and $3.5-8.7 \mathrm{~nm}$, and comparable full width at half maximum (FWHM) for the band located at the higher sizes, except for the sample composed of $20 \%$, which exhibits a FWHM in average $25 \%$ greater than the other ones. Moreover, in average, the second band is approximately 4 times greater than the one observed between 0.6 $0.9 \mathrm{~nm}$. First, this demonstrates that the developed materials are not composed of a homogenous molecular or oligomeric system, but is more likely a mixture of two molecular systems, explaining the observation of two bands in distinct size domains. From a previous study conducted by the authors using a similar material [7], it has been demonstrated that the bands located in the region $3.5-8.7 \mathrm{~nm}$ are characteristic of the formation of the silicate nanoparticles resulting from the hydrolysis and condensation reactions of the organosilane precursor. Consequently, the observed peaks located in the 0.6 - $0.85 \mathrm{~nm}$ size domain can be attributed to the formation of zirconium and aluminium/zirconium nanoparticles. Furthermore, the relative consistence FWHM of these bands translates that the size of the NPs does not rely on the concentration of the organometallic precursor. On the other hand, the greater FWHM for the 20\% sample symbolises the increase of the nanoparticles dispersion, certainly due to the increase of the condensation possibilities provided by the aluminium atom. Indeed, as demonstrated in a previous study [26], at ambient temperature, the formation of Si-O-Zr bonds is limited by steric hindrances, thus leading to the formation of two oligomeric systems $\left(\mathrm{SiO}_{2}\right.$ and $\left.\mathrm{ZrO}_{2}\right)$. In the present case, $\mathrm{Al}$ and $\mathrm{Si}$ atoms have very close physical properties (atomic weight and radius) enabling the formation of covalent oxo-bridges between both atoms (Si-O-Al). This is the most plausible explanation for the observation of the increase of FWHM and progressive shift of the band with the increase of Al concentration. Nevertheless, structural characterisations employing both ${ }^{29} \mathrm{Si}-\mathrm{NMR}$ and ${ }^{27} \mathrm{Al}-\mathrm{NMR}$ spectroscopies are required to highlight more fundamentally the various chemical reactions occurring in this system, which we expect to address in a future chemistry oriented study.

The SEM images of all coating systems appear to be consistent. A representative cross sectional view of $15 \%$ Al coating, prior to testing, is shown in Figure 3(A). The coating seems to be adhering properly to the substrate with no signs of delamination. The EDS analysis shown in Figure 3(B) demonstrates the presence of silicon, zirconium, aluminium and oxygen, thus confirming the successful incorporation of all metal precursor nanoparticles within the organosilane matrix, as well as the optimisation of the sol-gel process established in the materials development.

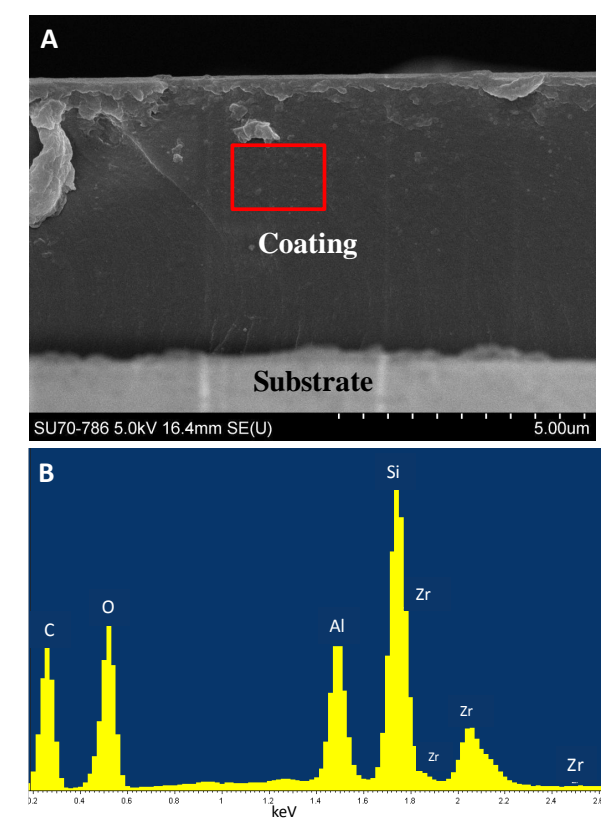

Figure 3. (A) SEM image of $15 \% \mathrm{Al}$ coating showing the coating and substrate; (B) EDS of the $15 \% \mathrm{Al}$ coating showing the presence of $\mathrm{Si}, \mathrm{Al}, \mathrm{Zr}$ and $\mathrm{O}$ (Red rectangle indicates the area of EDS study). 
XPS is a powerful technique to provide information about the elemental composition and chemical state of the coating surface, typically within its first 5 - $6 \mathrm{~nm}$, as defined by the penetration depth of X-ray. XPS spectrum shown in Figure 4 represents the characteristic peaks of the sol-gel coating. The spectrum shows the presence of $\mathrm{Si}(2 \mathrm{~s}, 2 \mathrm{p}), \mathrm{Zr}(3 \mathrm{~d}), \mathrm{Zr}(3 p), \mathrm{C}(1 \mathrm{~s})$ and $\mathrm{O}$ (1s) for all coatings. The formation of zirconium oxide $\left(\mathrm{ZrO}_{2}\right)$ during the hydrolysis and condensation process was confirmed by the detection of $\mathrm{Zr}$ (3d) and O (1s) peaks [27]. The presence of Si 2p and 2s peaks located at $102.3 \mathrm{eV}$ and $151.2 \mathrm{eV}$, respectively, confirms the formation of a siloxane network (Si-O-Si bonds). However, this spectrum shows no $\mathrm{Al}$ (2p) peaks corresponding to aluminium within the range $74.4-75.8 \mathrm{eV}$ [28] [29], thus suggesting that the aluminium rich nanoparticles are not present within 5 - $6 \mathrm{~nm}$ analysis volume available to the XPS technique at the air/sol-gel coating interface. Owing to these results, the most likely explanation could originate from the sedimentation of the aluminium rich nanoparticles toward the metal coating-interface. This phenomenon may have occurred during the deposition step, probably favoured by the formation of irreversible covalent aluminium oxide bonds ( $\mathrm{Al}-\mathrm{O}-\mathrm{Al}$ ) between the substrate and the sol-gel coating. However, as EDS analyses showed the presence of Al within the top 2 - 3 microns of a 5 microns coating, the complete sedimentation of the aluminium nanoparticles is thus impossible. This suggests that the concentration of aluminium based nanoparticles is gradually distributed within the sol-gel coating, from the top, where no aluminium could be detected to the metal/coating interface, where the concentration is probably maximum. This is a particularly essential result in the sol-gel science, as this demonstrates for the first time the effect of the metal nature on the homogeneity and concentration distribution of sol-gel coatings. Further investigations in order to quantify the distribution of the aluminium rich nanoparticles within sol-gel coatings along with their effects on the structure and morphology of the developed materials are in progress in our groups.

Figure 5 shows the visual images of the sol-gel coating surfaces after 72 hours exposure to a $\mathrm{pH}=10 \mathrm{NaCl}$ solution. The images clearly differentiate the performance of the various coatings at this $\mathrm{pH}$. The $10 \%$ and $15 \%$ Al doped systems were found to provide the highest anticorrosion performances with minimum or no visible

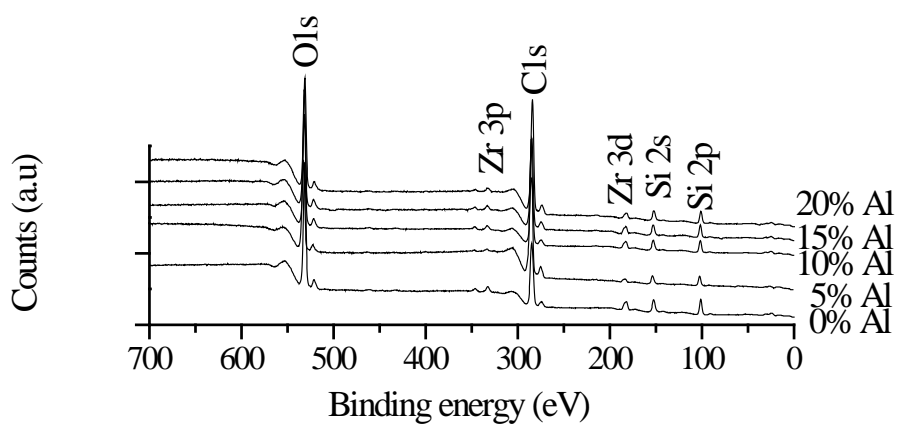

Figure 4. XPS characterisation of sol-gel coating with different concentration of $\mathrm{Al}$.

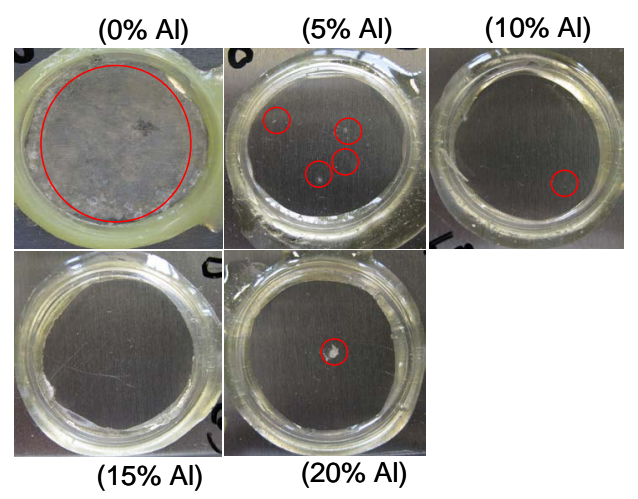

Figure 5. Visual images of sol-gel coated AA 2024-T3 alloy exposed to pH 10 after 72 hr (pitting sites circled in red). 
pitting, while the $0 \% \mathrm{Al}$ deteriorated completely in the same exposure conditions. The material containing the highest concentration of $\mathrm{Al}$ exhibited a major pitting indicating that the increase of $\mathrm{Al}$ provokes a significant change in the coating morphology, possibly resulting either from a decrease in the connectivity of the organosilane network or to a phase separation, the results of which would be an increase of the overall porosity enabling the penetration of the alkaline solution and the subsequent coating degradation.

Using Harrison's solution PDS evaluation involves applying a voltage from $0.5 \mathrm{~V}$ below the open circuit potential (cathodic region) to $0.4 \mathrm{~V}$ above it (anodic region). Therefore the degree of change in the current density (electrons exchange occurring at the electrodes) is a function of the potential applied. If a high enough potential (overpotential) is applied then corrosion is accelerated. Therefore a coating that maintains a low current density at high overpotential is desirable. The coating properties such as corrosion current densities $\left(I_{\text {corr }}\right)$ and potential $\left(E_{\text {corr }}\right)$ were estimated by the Tafel method [30], while the polarisation resistance $\left(R_{p}\right)$ was calculated using Stern-Geary equation [31] Equation (1):

$$
I_{\text {corr }}=B / R_{p}
$$

where $R_{p}$ is the polarisation resistance and $B$ is a proportionality constant for the particular system, which is calculated from the slopes of the anodic $\left(\beta_{a}\right)$ and cathodic $\left(\beta_{c}\right)$ Tafel regions, as shown by Equation (2):

$$
B=\beta_{a} \times \beta_{c} /\left[2.3\left(\beta_{a}+\beta_{c}\right)\right]
$$

$I_{\text {corr }}, E_{\text {corr }}$ and the Tafel coefficients for all coatings are listed in Table 2.

Figure 6 shows that the progressive inclusion of aluminium nanoparticles reduces the apparent current density for samples containing up to $15 \%$ of aluminium. Moreover, this current is higher by two orders of magnitude in comparison with uncoated AA 2024-T3 panels, as measured in a previous study [32]. The polarization resistance was also found to be greater by an order of magnitude for samples containing $10 \%$ and $15 \%$ aluminium in

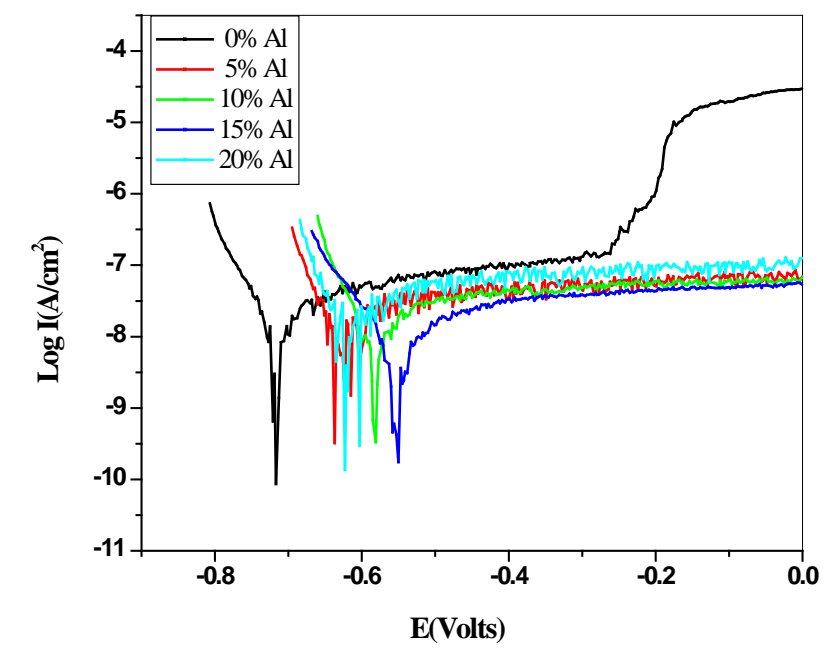

Figure 6. Potentiodynamic polarisation curves measured in Harrison's electrolyte for AA 2024-T3 coated sol-gel doped with various vol\% of $\mathrm{Al}$.

Table 2. The corrosion parameters for the Al doped sol-gel systems.

\begin{tabular}{cccccc}
\hline Sol-Gel Coatings & $\left|\beta_{a}\right|(\mathrm{V} /$ decade $)$ & $\left|\beta_{c}\right|(\mathrm{V} /$ decade $)$ & $I_{\text {corr }}\left(\mathrm{A} / \mathrm{cm}^{2}\right)$ & $E_{\text {corr }}(\mathrm{V})$ & $R_{p}\left(\Omega \cdot \mathrm{cm}^{2}\right)$ \\
\hline$\% \mathrm{Al}$ & 0.033 & 0.053 & $6.07 \times 10^{-09}$ & -0.713 & $6.19 \times 10^{6}$ \\
$5 \% \mathrm{Al}$ & 0.008 & 0.034 & $3.29 \times 10^{-09}$ & -0.641 & $1.51 \times 10^{6}$ \\
$10 \% \mathrm{Al}$ & 0.040 & 0.045 & $4.36 \times 10^{-09}$ & -0.579 & $3.65 \times 10^{7}$ \\
$15 \% \mathrm{Al}$ & 0.059 & 0.066 & $3.70 \times 10^{-09}$ & -0.536 & $6.47 \times 10^{7}$ \\
$20 \% \mathrm{Al}$ & 0.008 & 0.043 & $4.11 \times 10^{-09}$ & -0.615 & $1.10 \times 10^{6}$ \\
\hline
\end{tabular}


comparison with the other samples (Table 2). Furthermore, with little change in the $E_{\text {corr }}$ value, it is clear that the coating does not inhibit any electrochemical activity on the surface, but retards the ingress of water and/or oxygen. Therefore, it is proposed that until $15 \%$ of $\mathrm{Al}$, the inclusion of aluminium nanoparticles provokes an increase of the materials condensation, improving cross-linking and participating to the formation of a denser film. Additional increase of aluminium provokes the formation of larger nanoparticles, as demonstrated by the DLS measurements, with a subsequent decrease in the coating density.

\section{Conclusions}

Novel hybrid aluminium/zirconium sol-gel materials were prepared using organosilane, zirconium and aluminium-zirconium precursors while a constant level of metal precursors against the organosilane was maintained constant at $20 \mathrm{~mol} \%$.

The DLS technique clearly reveals the presence of two distinct particle distribution sizes, which prove that the developed systems are composed of a mixture of two molecular systems that coexist within the same matrix by the presence of physical interactions. The XPS results suggest that the aluminium rich nanoparticles are not present within 5 - $6 \mathrm{~nm}$ of the air/sol-gel coating interface; however SEM/EDX of cross section confirmed their presence within the bulk coating, demonstrating the gradual distribution of aluminium nanoparticles within the thickness coating. These results demonstrate for the first time the effect of the metal nature on the homogeneity and concentration distribution of sol-gel coatings. Further investigations will consist of quantifying the distribution of the aluminium rich nanoparticles within the sol-gel coatings along with their effects on the structure and morphology of the developed materials. On the other hand, the visual images and the electrochemical characterisations after exposure to high $\mathrm{pH}$ showed that samples containing $10 \%$ and $15 \%$ aluminium exhibited the best anticorrosion properties. This was attributed to the increase of the condensation of the materials, which were found greater for samples containing $10 \%$ and $15 \%$ aluminium. Additional increase of aluminium provokes the formation of larger nanoparticles, as demonstrated by the DLS measurements, with a subsequent decrease in the coatings densities. These results suggest these materials are promising environmentally friendly candidates as anticorrosion coatings for the protection of AA2024-T3 in challenging alkaline environments.

\section{References}

[1] Zhao, J., Xia, L., Sehgal, A., Lu, D., McCreery, R.L. and Frankel, G.S. (2001) Effects of Chromate and Chromate Conversion Coatings on Corrosion of Aluminum Alloy 2024-T3. Surface and Coatings Technology, 140, 51-57. http://dx.doi.org/10.1016/S0257-8972(01)01003-9

[2] Metroke, T.L., Gandhi, J.S., Apblett, A. (2004) Corrosion Resistance Properties of Ormosil Coatings on 2024-T3 Aluminum Alloy. Progress in Organic Coatings, 50, 231-246. http://dx.doi.org/10.1016/j.porgcoat.2004.03.001

[3] Voevodin, N.N., Grebasch, N.T., Soto, W.S., Arnold, F.E. and Donley, M.S. (2001) A Comparative Evaluation of Corrosion Protection of Sol-Gel Based Coatings Systems. Surface and Coatings Technology, 140, 16-23. http://dx.doi.org/10.1016/S0257-8972(01)00998-7

[4] Twite, R.L. and Bierwagen, G.P. (1998) Review of Alternatives to Chromate for Corrosion Protection of Aluminum Aerospace Alloys. Progress in Organic Coatings, 33, 91-100. http://dx.doi.org/10.1016/S0300-9440(98)00015-0

[5] Jerman, I., Vuk, A.S., Kozelj, M., Orel, B. and Kovec, J. (2008) A Structural and Corrosion Study of Triethoxysilyl Functionalized POSS Coatings on AA 2024 Alloy. Langmuir, 24, 5029-5037. http://dx.doi.org/10.1021/la7037262

[6] Zheludkevich, M.L., Salvado, I.M. and Ferreira, M.G.S. (2005) Sol-Gel Coatings for Corrosion Protection of Metals. Journal of Materials Chemistry, 15, 5099-5111. http://dx.doi.org/10.1039/b419153f

[7] Versace, D.L., Oubaha, M., Copperwhite, R., Croutxé-Barghorn, C. and MacCraith, B.D. (2008) Waveguide Fabrication in UV-Photocurable Sol-Gel Materials: Influence of the Photoinitiating System. Thin Solid Film, 516, 6448-6457. http://dx.doi.org/10.1016/j.tsf.2008.02.028

[8] Rajath Varma, P.C., Colreavy, J., Cassidy, J., Oubaha, M., Duffy, B. and McDonagh, C. (2009) Effect of Organic Chelates on the Performance of Hybrid Sol-Gel Coated AA 2024-T3 Aluminium Alloys. Progress in Organic Coatings, 66, 406-411. http://dx.doi.org/10.1016/j.porgcoat.2009.09.004

[9] Parkhill, R.L., Knobbe, E.T. and Donley, M.S. (2001) Application and Evaluation of Environmentally Compliant Spray-Coated Ormosil Films as Corrosion Resistant Treatments for Aluminum 2024-T3. Progress in Organic Coatings, 41, 261-265. http://dx.doi.org/10.1016/S0300-9440(01)00138-2

[10] Kasemann, R. and Schmidt, H. (1993) Coatings for Mechanical and Chemical Protection Based on Organic-Inorganic Sol-Gel Nanocomposites. First European Workshop on Hybrid Organic-Inorganic Materials, Chateau de Bierville, 
8-10 November 1993, 171-180.

[11] Varma, P.C.R., Colreavy, J., Cassidy, J., Oubaha, M., McDonagh, C. and Duffy, B. (2010) Corrosion Protection of AA 2024-T3 Aluminium Alloys Using 3,4-Diaminobenzoic Acid Chelated Zirconium-Silane Hybrid Sol-gels. Thin Solid Films, 518, 5753-5761.

[12] Oubaha, M., Kavanagh, A., Bickauskaite, G., Gorin, A., Farsari, M., McDonagh, C., Byrne, R., Diamond, D. and Copperwhite, R. (2012) Graphene-doped photo-patternable ionogels: tuning of conductivity and mechanical stability of 3D microstructures. Journal of Materials Chemistry, 22, 10552-10559. http://dx.doi.org/10.1039/c2jm30512g

[13] Voevodin, N.N., Grebasch, N.T., Soto, W.S., Kasten, L.S., Grant, J.T., Arnold, F.E. and Donley, M.S. (2001) An Organically Modified Zirconate Film as a Corrosion-Resistant Treatment for Aluminum 2024-T3. Progress in Organic Coatings, 41, 287-293. http://dx.doi.org/10.1016/S0300-9440(01)00156-4

[14] Blohowiak, K.Y., Krienke, K.A. and Osborne, J.H. (1996) Sol for Coating Metals. US Patent No. 5814137A.

[15] Colreavy, J., Duffy, B., Varma, P.C.R., Hayden, H. and Oubaha, M. (2006) Organosilane Coating Compositions and Use Thereof. US7994249 B2.

[16] Hirai, S., Shimakage, K., Sekiguchi, M., Wada, K. and Nuku, A. (1999) Zirconium Oxide Coating on Anodized Aluminum by the Sol-Gel Process Combined with Ultraviolet Irradiation at Ambient Temperature. Journal of the American Ceramic Society, 82, 2011-2015. http://dx.doi.org/10.1111/j.1151-2916.1999.tb02033.x

[17] Zhu, D.Q. and van Ooij, W.J. (2003) Corrosion Protection of AA 2024-T3 by Bis-[3-(triethoxysilyl)propyl]tetrasulfide in Sodium Chloride Solution: Part 2: Mechanism for Corrosion Protection. Corrosion Science, 45, 2177-2197. http://dx.doi.org/10.1016/S0010-938X(03)00061-1

[18] Bibber, J.W. (1998) An Update on Chrome-Free Pretreatments for Aluminium. Metal Finishing, 96, 28. http://dx.doi.org/10.1016/S0026-0576(97)86639-1

[19] Kumar, G. and Buchheit, R.G. (2006) Development and Characterization of Corrosion Resistant Coatings Using the Natural Biopolymer Chitosan. ECS Transactions, 1, 101-117. http://dx.doi.org/10.1149/1.2215582

[20] Zheludkevich, M.L., Serra, R., Montemor, M.F., Yasakau, K.A., Miranda Salvado, I.M. and Ferreira, M.G.S. (2005) Nanostructured Sol-Gel Coatings Doped with Cerium Nitrate as Pre-Treatments for AA2024-T3: Corrosion Protection Performance. Electrochimica Acta, 51, 208-217. http://dx.doi.org/10.1016/j.electacta.2005.04.021

[21] Andreatta, F., Paussa, L., Aldighieri, P., Lanzutti, A., Raps, D. and Fedrizzi, L. (2010) Corrosion Behaviour of Sol-Gel Treated and Painted AA2024 Aluminium Alloy. Progress in Organic Coatings, 69, 133-142. http://dx.doi.org/10.1016/j.porgcoat.2010.04.012

[22] Kartsonakis, I.A., Balaskas, A.C. and Kordas, G.C. (2011) Influence of Cerium Molybdate Containers on the Corrosion Performance of Epoxy Coated Aluminium Alloys 2024-T3. Corrosion Science, 53, 3771-3779. http://dx.doi.org/10.1016/j.corsci.2011.07.026

[23] Varma, P.C.R., Duffy, B. and Cassidy, J. (2009) Influence of Magnesium Nitrate on the Corrosion Performance of Sol-Gel Coated AA2024-T3 Aluminium Alloy Original Research Article. Surface and Coatings Technology, 204, 277-284.

[24] Chung, Y.J., Hon, M.M. and Kendig, M.W. Nano-Structured Inorganic Zinc Phosphate Corrosion Protective Coating for Metal Alloys. US7579049 B2.

[25] Li, L.J., Pi, P.H., Wen, X.F., Cheng, J. and Yang, Z.R. (2008) Aluminum Pigments Encapsulated by Inorganic-Organic Hybrid Coatings and Their Stability in Alkaline Aqueous Media. Journal of Coatings Technology and Research, 5, 77-83. http://dx.doi.org/10.1007/s11998-007-9053-9

[26] Oubaha, M., Smaihï, M., Etienne, P., Coudray, P. and Moreau, Y. (2003) Spectroscopic Characterization of Intrinsic Losses in an Organic-Inorganic Hybrid Waveguide Synthesized by the Sol-Gel Process. Journal of Non-Crystalline Solids, 318, 305-313. http://dx.doi.org/10.1016/S0022-3093(02)01889-6

[27] Chang, S. and Doong, R. (2005) ZrO2 Thin Films with Controllable Morphology and Thickness by Spin-Coated SolGel Method. Thin Solid Films, 489, 17-22. http://dx.doi.org/10.1016/j.tsf.2005.04.076

[28] Kim, Y.C., Park, H.H., Chun, J.S. and Lee, W.J. (1994) Compositional and Structural Analysis of Aluminum Oxide Films Prepared by Plasma-Enhanced Chemical Vapor Deposition. Thin Solid Films, 237, 57-65. http://dx.doi.org/10.1016/0040-6090(94)90238-0

[29] Rajopadhye, N.R., Dake, S.B. and Bhoraskar, S.V. (1994) Characterization of $\mathrm{Al}_{2} \mathrm{O}_{3}$ Films Deposited by Various Methods. Thin Solid Films, 142, 127-138. http://dx.doi.org/10.1016/0040-6090(86)90308-1

[30] Kendig, M., Jeanjaquet, S., Addison, R. and Waldrop, J. (2001) Role of Hexavalent Chromium in the Inhibition of Corrosion of Aluminum Alloys. Surface and Coatings Technology, 140, 58-66. http://dx.doi.org/10.1016/S0257-8972(01)01099-4

[31] Barranco, V., Feliu Jr., S. and Feliu, S. (2004) EIS Study of the Corrosion Behaviour of Zinc-Based Coatings on Steel 
in Quiescent 3\% NaCl Solution. Part 1: Directly Exposed Coatings. Corrosion Science, 46, 2203-2220. http://dx.doi.org/10.1016/j.corsci.2003.09.032

[32] Varma, P.C.R., Periyat, P., Oubaha, M., McDonagh, C. and Duffy, B. (2011) Application of Niobium Enriched Ormosils as Thermally Stable Coatings for Aerospace Aluminium Alloys. Surface \& Coatings Technology, 205, 39923998. http://dx.doi.org/10.1016/j.surfcoat.2011.02.023 